\title{
Corpo e gramática: abordagens para o estudo de recursos expressivos corporificados
}

\author{
Taís BOPP DA SILVA 『 \\ Universidade Federal de Pelotas (UFPel)
}

\section{RESUMO}

Esta resenha visa a apresentar e comentar três pesquisas reunidas na mesa-redonda intitulada "O corpo na gramática: gestos na construção dos sentidos". Os referidos estudos possuem como interesse comum a dimensão corporal da linguagem como meio de produção de sentidos. São três as abordagens trazidas pelos pesquisadores: (1) uma de cunho sociolinguístico, (2) outra de feição cognitivo-interacionista e intercultural e, por fim, (3) uma terceira, relacionada à variação intracultural de gestos emblemáticos. A utilização de tecnologias para sanar problemas até então tratados marginalmente no âmbito da ciência linguística também constitui

EDITADO POR Raquel Freitag

REVISADO POR

Regina Cruz

DATAS

Recebido: 04/06/2020 Aceito: $14 / 06 / 2020$ Publicado: 08/07/2020

COMO CITAR

Bopp da Silva, T. (2020). Corpo e gramática: abordagens para o estudo de recursos

expressivos corporificados. Revista da Abralin, v. 19, n. 2, p. 1-5, 2020. ponto de intersecção entre os trabalhos aqui expostos. Espera-se que a presente resenha possa motivar o leitor a buscar maiores informações sobre as pesquisas analisadas neste espaço.

\section{ABSTRACT}

This review aims to present and comment on three studies gathered at the round table entitled "The body on grammar: gestures in the construction of senses". These studies have a common interest in the role of body language as a means of producing meanings. The researchers presented three approaches: (1) a sociolinguistic approach, (2) a cognitive-interactionist and intercultural perspective and (3) an intracultural approach, focused on variation of emblematic gestures. The use of technologies to solve problems so far marginally addressed in the scope of linguistic science is also an intersection point between the investigations exposed here. The purpose of this 


\section{REVISTA DA ABRALIN}

review is to motivate other researchers to seek more information about the topics presented here.

\section{PALAVRAS-CHAVE}

Expressões faciais. Recursos corporificados. Gestos emblemáticos.

\section{KEYWORDS}

Facial expressions. Embodied resources. Emblematic gestures.

Epifenômenos linguísticos, historicamente, têm sido colocados à margem na agenda de preocupações da Linguística e mesmo de outras disciplinas que tratam da linguagem, como a Psicologia e a Filosofia. Não que linguistas - de quem se esperaria o pioneirismo neste campo de pesquisas - não reconhecessem a necessidade de prover tratamento aos fenômenos ligados aos sinais "supraverbais", representados pelas expressões corporais e faciais e pela gestualidade, que comunicam silenciosamente. Acontece que, para que se avance na ordem do dia, é necessário que um problema seja reconhecido em sua magnitude e em suas implicações para a resolução de outros problemas. Também é preciso que condições metodológicas sejam satisfeitas.

Os pesquisadores Raquel Freitag (UFS/CNPq), Thiago Nascimento (UFMG-ICMI), e Regina Cruz (UFPA/CNPq), em sua mesa-redonda intitulada "O corpo na gramática: gestos na construção dos sentidos", brindaram a comunidade de linguistas conectados ao "ABRALIN ao vivo" com a apresentação de trabalhos que constituem propostas consistente para que se avance no estudo da dimensão corporal da linguagem. São trabalhos inovadores, de extrema relevância e com potencial para muitas colaborações, dada a originalidade dos temas no Brasil.

Raquel Freitag, em sua fala, apresenta algumas propostas para tratamento metodológico da ambiguidade nas abordagens pragmático-discursivas da linguagem. Diferentemente dos estudos de gramática, em que a resolução da ambiguidade é demonstrada, analiticamente, pela via do processamento linguístico, nos estudos contextuais, em que pistas de desambiguização são fornecidas por elementos paralinguísticos e pelos recursos corporificados, o tratamento da ambiguidade de forma sistemática se apresenta como um problema. Freitag caracteriza o sentido como um epifenômeno linguístico, ou seja, como um envelope no qual se integram pistas linguísticas e pistas corporais (expressões faciais e gestuais), sendo a separação e a hierarquização destes elementos decorrente de opções analíticas e restrições metodológicas. De fato, estas últimas parecem constituir o principal entrave a análises da produção de sentido.

Indo ao encontro de tal problemática, a pesquisadora apresenta o estudo em andamento "A face do preconceito: processamento da variação linguística", voltado para a construção de um banco de dados de expressões faciais capaz de auxiliar pesquisadores a mapear reações emocionais e pistas linguísticas. Visto que o Brasil ainda não conta com um banco de dados deste tipo, o ponto de 


\section{REVISTA DA ABRALIN}

referência para estudiosos que pretendem investigar expressões de emoções entre falantes brasileiros é um banco de dados europeu. Nesse sentido, Raquel Freitag conduz um projeto inovador e de extrema relevância, ao construir uma base de dados para estudo de epifenômenos linguísticos adequada à realidade sociocultural brasileira. Ainda que as expressões faciais de emoções sejam propaladas como sendo culturalmente universais, não há dados robustos a partir dos quais se possa fazer tal afirmação. Nesse aspecto, a investigação de Freitag também representa uma importante contribuição para o estudo das emoções e seus aspectos culturais e universais. Os esforços empregados pela pesquisadora e seu grupo para a composição deste banco de dados, todavia, não visam a mera catalogação de expressões faciais: buscam compreender o lugar do corpo na gramática. Raquel Freitag parte da ideia de que os recursos corporificados e expressões faciais também podem ser sistematizados e, por conseguinte, seu uso é governado por regras, assim como a gramática. Seu objetivo, portanto, é contribuir para a a resolução da problemática acerca de como integrar linguagem verbal e linguagem corporal de forma objetiva e metodologicamente viável.

Na linha da Linguística Cognitivo-Interacional, utilizando elementos da Linguística Cognitiva, Thiago Nascimento apresenta o estudo "O corpo na fala-em-interação: uma análise cognitivo-interacional", que trata do sincronismo entre as atitudes comunicativas, expressas no nível cognitivo, ou seja, no nível da língua, e os recursos corporificados, atuantes no nível metacomunicativo. A pergunta que conduz o estudo de Nascimento é: de que forma os participantes de uma interação fazem uso de recursos corporificados para realizar ações metacomunicativas? Recursos corporificados podem ser entendidos como meios de expressão viabilizados pelo corpo - tais como gestos, olhares, postura, movimentos de corpo e de cabeça - com o propósito de engendrar ações na interação. São utilizados pelos atores interactantes para desambiguizar, manter e negociar sentidos, produzindo efeitos em conjunto com a linguagem verbal, e também como recursos para o gerenciamento interpessoal, por meio do monitoramento da aceitabilidade de outros atos de comunicação. Lançar mão de recursos corporificados como conceitos operacionais para o estudo de interações permite ao pesquisador o empreendimento de análises mais holísticas do que aquelas restritas a dados fornecidos pela superfície linguística. Com a adoção deste arsenal teórico aliado a novas tecnologias audiovisuais, Nascimento traz inestimáveis contribuições aos estudos de análise em interação. A partir desses avanços, este campo de pesquisa, que contava fundamentalmente com material sonoro e valia-se de pistas muito intuitivas para analisar fenômenos de natureza visual, tem agora novas possibilidades de tratamento eficazes para outras pistas comunicativas.

Por último, na sequência de exposições, Regina Cruz traz os resultados parciais do estudo em desenvolvimento "Quando o corpo fala: mapeamento de gestos emblemáticos em comunidades de prática de Pernambuco e Alagoas", realizado no âmbito de seu grupo de pesquisa. As comunidades em estudo são a de surdos bilíngues Libras/português, a de quilombolas e a de indígenas, todas compostas de falantes de língua portuguesa e residentes em território brasileiro. O objetivo geral da pesquisa é verificar o caráter variacional de gestos emblemáticos em um contexto intracultural. Lascarides e Stone (2009) consideram dois tipos de gestos, a saber, os gestos ilustradores, que coocorrem com a fala, e os gestos emblemáticos. Estes últimos prescindem da fala para manifestar seu 


\section{REVISTA DA ABRALIN}

sentido e, além disso, apresentam significado estável e compartilhado socialmente, tal como o signo linguístico. Segundo Matsumoto e Hwang (2013), interculturalmente, um mesmo gesto emblemático pode carregar diferentes significados, um mesmo significado pode ser expresso por diferentes gestos emblemáticos, ou, mesmo, podem existir gestos emblemáticos específicos a culturas particulares. A pergunta que o estudo de Cruz buscar resolver, contudo, é se essa variabilidade de gestos emblemáticos pode ser encontrada dentro de uma mesma cultura. A pesquisadora, ao promover um estudo variacionista acerca de dados não verbais, apresenta importante inovação no âmbito da linguística brasileira, visto que os estudos de variação no Brasil são estudos predominantemente de estruturas linguísticas. Além disso, sua pesquisa visa a contribuir com a linguística nacional no sentido de apresentar à comunidade de pesquisadores um banco de dados de gestos emblemáticos utilizados entre falantes do português brasileiro. Ainda que seu estudo se encontre em andamento, alguns resultados indicam a existência de formas variáveis dos gestos emblemáticos dentro da cultura brasileira.

Os três estudos acima expostos representam relevantes contribuições científicas com promissores impactos sociais. Destaca-se, em primeiro lugar, que as três pesquisas concorrem para consolidar o corpo como um nível de análise linguística. Isto é possível porque o aparato tecnológico utilizado pelos pesquisadores, como a gravação digital em vídeo e o uso de softwares e scanners, permite aos estudiosos operacionalizar eventos até então tratados com imprecisão, como as expressões faciais. Este importante passo dentro da ciência linguística permite que floresçam uma gama de estudos inovadores em Linguagem-em-Interação, Sociolinguística, Pragmática, Linguística Cognitiva, Psicolinguística, dentre outras disciplinas que precisam olhar para fatores paralinguísticos. Adicionalmente, alguns campos da Psicologia se beneficiam com este progresso, como o campo das emoções e da cognição social.

Um outro aspecto a destacar nos três trabalhos é sua preocupação de mapear a realidade linguístico-cultural brasileira. É sabido que a adoção de modelos teórico-analíticos idealizados em uma dada realidade sociocultural pode resultar em distorções quando tais modelos são transpostos para a análise de fatos de outras realidades. Guiar-se pelas próprias bússolas - ou seja, utilizar as ferramentas adequadas para a compreensão de uma realidade particular - é uma tendência que vem se disseminando nas Ciências Humanas e com a qual a Linguística necessita se afinar. Descolonizar o conhecimento é preciso. E esse novo paradigma é exemplar nos estudos aqui examinados.

Ganhando a ciência, ganha a sociedade. Uma vez que a linguagem, por meio de seus dispositivos verbais e não verbais, constitui ferramenta social e cultural que comunica, constrói identidades e executa atos, nada mais importante que desvelar seus mecanismos de funcionamento. Reconhecer como legítimas todas as dimensões do aparato comunicativo contribui para que se reconheçam as necessidades, as intenções e os desejos dos seres comunicantes. E esse pode ser um passo na direção da construção de um mundo de bem-estar social. Não é demais lembrar que certas mensagens hostis que circulam na sociedade nem sempre estão explicitadas na linguagem verbal. Muitas vezes, um dizer aparentemente benevolente adquire um sentido implícito ultrajante a depender da configuração corporal do falante. Em diversos casos, é difícil detectar estas pistas claramente e, assim, 


\section{REVISTA DA ABRALIN}

denunciar os agentes que fazem uso desses recursos para espalhar ideias de intolerância. Nesse sentido, incluir o corpo e suas configurações no campo de interesses da Linguística é de extrema importância no sentido de se fazer reconhecer os significados velados que as mensagens corporificadas podem veicular. Conhecer o poder da linguagem do corpo, portanto, representa um avanço não apenas para a Linguística, mas para a construção de uma sociedade mais comprometida com o respeito e a dignidade.

\section{REFERÊNCIAS}

LASCARIDES, A.; STONE, M. A formal semantic analysis of gesture. Journal of Semantics, v. 26, p. 393-449, 2009.

MATSUMOTO D.; HWANG H. C. Cultural similarities and differences in emblematic gestures. Journal of Nonverbal Behaviour, v. 37, n. 1, p. 1-27, 2013.

O corpo na gramática: gestos na construção dos sentidos. Conferência apresentada por Raquel Freitag, Thiago Nascimento e Regina Cruz [s.l., s.n], 2020. 1 vídeo (2h 12min 55s). Publicado pelo canal da Associação Brasileira de Linguística. Disponível em: https://www.youtube.com/watch?v=xXgjh1CDAGU\&t=6097s. Acesso em: 27 mai 2020 . 